\title{
Erratum to: Multi-layer Pavement System under Blast Load
}

\section{Erratum to:}

J. Wu and H. Wu, Multi-layer Pavement System under

Blast Load, Springer Tracts in Civil Engineering, https://doi.org/10.1007/978-981-10-5001-5

In the original version of the book, "Acknowledgement" and the following author names and their corresponding affiliations have to be newly included in frontmatter:

Hong Wei Andy Tan, Manager, Land Transport Authority, No. 1 Hampshire Road, 219428 Singapore.

Soon Hoe Chew, Assistant Professor, Department of Civil and Environmental Engineering, National University of Singapore, No. 21 Lower Kent Ridge Road, 119077 Singapore.

The erratum book has been updated with the changes.

The updated online version of this book can be found at https://doi.org/10.1007/978-981-10-5001-5 